Jurnal Keperawatan Padjadjaran

ISSN 2338-5324 (print)

ISSN 2442-7276 (online)

Online di http://jkp.fkep.unpad.ac.id

DOI : $10.24198 / \mathrm{jkp}$

\title{
Exploring of Nurses' Needs of New Design Intravenous System Device to Support Nursing Care Effectively
}

\author{
Yesiana Dwi Wahyu Werdani ${ }^{1}$, Hartono Pranjoto ${ }^{2}$, Lanny Agustine ${ }^{2}$, Diana Lestariningsih ${ }^{2}$ \\ ${ }^{1}$ Faculty of Nursing Widya Mandala Catholic University Surabaya, Surabaya, Indonesia \\ ${ }^{2}$ Faculty of Engineering Widya Mandala Catholic University Surabaya, Surabaya, Indonesia \\ Corresponding email: ywerdani@yahoo.com
}

Submitted: 13-04-2020 Accepted: 15-06-2020 Published: 01-08-2020

\begin{abstract}
Fluid control is important to support the success of therapy in the hospital. The existing features of the device currently do not fully support to ease the work of nurses. It is necessary to explore deeply the nurse's need for the features of a new device intravenous system. The purpose of this study was to explore the nurse's need for new design intravenous system devices to support nursing care effectively This was a qualitative study with thematic analysis methods. The participants were 20 nurses in Gotong Royong Hospital Surabaya taken by purposive sampling method. Data were collected by an in-depth interview. The instrument consists of structured questions. The interviews were recorded by a digital recorder. Ethical requirements are completed before data collection. This study found 4 themes consist of the economical price, multi-automatically system, flexible design, and simplicity. The nurse's needs for a new design intravenous system device was designed more economical than today's sophisticated device, and have more complete of automatic system, flexible and easy to use. These features match the needs expected by nurses and further assist in carrying out the nursing care process effectively and efficiently.
\end{abstract}

Keywords: Automatically, device, economical, intravenous system, nursing care. 
Yesiana Dwi Wahyu Werdani: Exploring of Nurses' Needs of New Design Intravenous System Device

\section{Introduction}

Giving intravenous fluid therapy is a collaborative action between nurses and physicians. It is an important part of the nursing care plan because the management of fluid therapy has to administer appropriately. The infusion pump was an effective device to provide fluid, blood, and treatment to patients, it contributed to improving the quality of patient care because of the greater level and accuracy to reduce medication errors (Padmaja \& Kalgal, 2013). If it could not running well, it causes a variety of adverse side effects to patients. Currently there are many medical devices to control intravenous fluids automatically, but these tools do not fully feature to help ease the work of nurses and each error often in its implementation. A study stated that even the automatic infusion pump program, there was still a large portion of programming that was done manually (Scott Evans et al., 2010). Another study stated that nurses made mistakes in administering drugs through smart pump infusions $(58 \%)$, this was because the pump programming still used manual mathematical calculations performed by nurses (Trbovich et al., 2010). This was more complicated and can cause high risk of errors when the workload of nurses was high in every shift. Previous studies declared that 105 nurses at Nishtar Medical College and Multan Hospital in Pakistan experienced nurses' workload performance with high average consumption time in the implementation of nursing care activities in the morning shift $(57.10 \%)$ and evening $(52.1 \%)$, this is higher than the night shift that only has an average consumption time with non-nursing activities (Safdar et al., 2019).

A study of 634 patients with intravenous drug and infusion therapy found an error rate of 1.4 times. It showed that the human error towards therapeutic programming conducted by high health workers such as nurses (Morales-González \& Galiano Gálvez, 2017). In a study to 40 nurses in charge of administering intravenous fluid therapy in an adult intensive care unit, several errors were found such as errors in the setting and programming of primary continuous intravenous infusion, errors in identifying veins for infusion therapy, flush rate errors after intravenous injection, errors in preparing secondary intravenous infusions, and errors in administering intravenous pump boluses (Pinkney et al., 2014). Another study reported that failure to use an intravenous smart pump in reducing intravenous medication error, due to inappropriate features (Nuckols et al., 2008).

Expensive costs are one of the problems that cause hospitals to only have a limited supply of smart pumps. A study stated that for the average patient's utility costs, continuous infusion pumps have a total cost of $€ 199,296$ (Quitian et al., 2015). The operational costs of managing and maintaining the use of infusion pumps have very high costs, therefore most of the infusion pumps in hospitals are in storage and are rarely exchanged between departments, the maintenance process is not monitored so it is not clear whether the current level of care meets the infusion pump maintenance regulations or not (Kemper et al., 2009). Most hospitals only use infusion control devices in certain units such as the intensive care unit (ICU). Several studies stated that research on smart pumps was carried out in the ICU because the majority of the use of these devices is only done in critical units (Giuliano, 2018; ManriqueRodríguez et al., 2013).

In previous study on intravenous therapy, it was stated that the technology used demands additional cognitive abilities from doctors and nurses, causing failure in the use of tools and obstacles that arise in the device are not easily detected (Cassano-Piché et al., 2012). A study of smart intravenous pumps implemented in academic hospitals stated that initially the use of only a few nurses had positive acceptance of the smart intravenous pump technology, and that over time there was no significant increase in nurse's acceptance (Carayon et al., 2010). This proves that the creation of new design devices that are not based on the needs of nurses will be able to cause a mismatch of features in the device. When will design a more effective device, further exploration is needed about the features of the device to facilitate the work of nurses. Almost all of the previous studies that have been described above do trials to health workers on the effectiveness 
of infusion pump devices that are designed with a variety of technologies, but there was no research that explores further what exactly was needed by health workers, especially nurses on technology, a new device about smart infusion pump.

The purpose of this study was to explore the nurse's need for new design intravenous system devices to support effective nursing care effectively.

\section{Method}

This study was a qualitative study used COREQ guideline to hold the research, with thematic analysis method. This method was used to obtain descriptions from participants by identifying patterns and finding themes through collected data.

The populations were 25 nurses in Gotong Royong Hospital Surabaya, to be able to provide a realistic description of the nurse's need for a new design of intravenous system device with expected features. Samples were selected from the population used purposive sampling through inclusion criteria consist of 1) nurses who had work experience at least 1 year, 2) nurses who had the minimum educational background was a diploma, 3) nurses who have done installation and monitoring of infusion more than 5 times, 4) nurses who have ever operated a manual infusion installation and automatic infusion pump. Nurses who appropriate with the inclusion criteria then approached by the researcher by explaining the objectives, benefits, and research procedures, and freedom of participation in this research. Nurses who were willing to be respondents then asked to sign an informed consent sheet as a form of consent. The sample size was 20 nurses based on inclusion criteria. Some 5 nurses were taken out as respondents because they just worked for less than 1 year.

Data were collected by an in-depth interview. The interview process did by the researcher. The researcher is female and worked as a lecturer and the researcher's relationship with the respondents before the research was conducted was a working relationship. This hospital is one of the hospitals which is used as a place for student practices area where researchers work and researcher as an academic preceptor in this hospital. The interviews were conducted in the nursing room, only the researcher and one nurse in this room and interview process recorded by a digital recorder. Researchers asked some questions to respondents based on structured question guidelines made by researchers, and respondents provide open answers. Each interview process lasted on average of 20 minutes and the researcher didn't make interruption during the interview process.

After the interview results were recorded, then it was transcribed verbatim by researchers and typed in Microsoft Word. The next step researcher did the coding process. The coding process method used was in vivo code that was the researcher wrote the code by the words used by participants. After all the code was completed, then continue to be evaluated again to find the code relevant to the research. When all the data has been coded, the codes that have the same meaning were made into groups. After that researcher selected the theme, the researcher reviews all the codes and groups that have been formed to ensure that the codes within each group have the same meaning. Groups that have a common meaning are collected into a theme. The last stage was to determine the conclusions/ verification of analysis results. Ethics Approval and Consent to Respondents

This study has been carried out the ethical tests conducted by medical faculty of Widya Mandala Catholic University and stated ethical. Explanation of the research procedures, purposes, advantages, and riskinformed to participants and signing the informed consent who agreed as participants.

\section{Discussion}

To create a new design intravenous system device, it was needed input from nurses about the various features expected. Based on the results in table 3 found that participants asked the economical price of the ecosmart intravenous device, they expected the device to be designed with quality materials but the selling price can be affordable to be programmed in patients and to be invested 
Yesiana Dwi Wahyu Werdani: Exploring of Nurses' Needs of New Design Intravenous System Device

\section{Results}

Table 1 Demographic Characteristic

\begin{tabular}{lc}
\hline \multicolumn{1}{c}{ Demographic Data } & Result \\
\hline Age, year (mean + SD) & $30+6.3$ \\
Gender & \\
Female & $19(95 \%)$ \\
Male & $1(5 \%)$ \\
Length of working & \\
$1-3$ years & $8(40 \%)$ \\
$4-6$ years & $8(40 \%)$ \\
More than 6 years & $4(20 \%)$ \\
\hline
\end{tabular}

Table 2 Main Themes and Categories

\begin{tabular}{ll}
\hline \multicolumn{1}{c}{ Themes } & \multicolumn{1}{c}{ Category } \\
\hline 1. Economical Price & Economical price for patients \\
& Economical price for hospitals \\
2. Multi-Automatically System & Stops automatically \\
& Monitoring remaining intravenous fluids \\
& automatically \\
& Drops calculate automatically \\
& Alarm system automatically \\
& Internet monitoring \\
3. Flexible design & Flexible for mobility \\
4. Simplicity & Easy to use \\
\hline
\end{tabular}

Table 3 Participant's narratives

\begin{tabular}{ll}
\hline \multicolumn{1}{c}{ Themes/ Category } & \multicolumn{1}{c}{ Participant's Narratives } \\
\hline Theme 1: Economical price & \\
Category & $\begin{array}{l}\text { Participant } 4 \text { said: "Other devices could not be used } \\
\text { for patients with poor economic status, because of } \\
\text { expensive hire costs, this new device should be cheaper } \\
\text { to be used for all patients who receiving intravenous } \\
\text { therapy with various economic status" } \\
\text { Economical price for patients }\end{array}$ \\
$\begin{array}{l}\text { Participant } 7 \text { said: "This device should be marketed at } \\
\text { an affordable price to be purchased by the manager of } \\
\text { a hospital to the hospital has a lot of stock that could be } \\
\text { used by all patients" }\end{array}$ \\
$\begin{array}{l}\text { Economical price for hospitals } \\
\text { Theme 2: Multi-Automatically System }\end{array}$ \\
$\begin{array}{l}\text { Category } \\
\text { Stops automatically }\end{array}$ \\
$\begin{array}{l}\text { All participants expected that the device could stop } \\
\text { automatically when the intravenous fluid runs out, to } \\
\text { prevent air embolism. }\end{array}$ \\
\hline
\end{tabular}


Yesiana Dwi Wahyu Werdani: Exploring of Nurses’ Needs of New Design Intravenous System Device

Monitoring remaining intravenous fluids automatically

Drops calculate automatically

Alarm system

Internet monitoring

\section{Theme 3: Flexible design}

\section{Category}

Flexible for mobility

Theme 4: Simplicity

\section{Category}

Easy to use

by hospitals. Currently the use of intravenous pumps has only been provided to patients who have special problems such as patients in the Intensive Care Unit. Even though in the inpatient ward the use of infusion pumps should also be done to improve patient safety. But in reality in the inpatient ward is never done because the cost of hiring the device to be paid by patients is very expensive, besides the sale price of the equipment is also expensive which causes the hospital does not have enough funds to provide infusion pump equipment in large quantities. A study stated that hospital financial resources are limited, it causing hospitals cannot be able to provide infusion pumps that have an automatic ability to calculate drugs and infusion rates,
Participant 12 said:

"During this time, nurses check the remaining fluid manually by looking at the infusion bottle, but the new device is expected to be monitored through the screen on the device"

Participant 3 said:

"To facilitate the work of nurses, so the new device must be able to automatically count the drip like an existing infusion pump"

All participants expected that the device equipped with an alarm system to be able to detect if the infusion fluid runs out or when there are an infusion flow obstacles, to that nurses could easily take immediate action to overcome it

Participant 12 said:

This new device should be able to monitor the intravenous fluids at the nurse station through the internet network

Participant 1 said:

"This device should be flexible and can be used by patients who have started learning wheelchair mobilization"

Participant 16 said:

"This device must have a quality battery so that if the light turn of or when the patient delivered to the radiology room/ physiotherapy room it can still be used without electricity"

Participant 13 said:

"The device must be easily operated by new nurses without special training"

Participant 8 said:

"The device must be designed in a sophisticated yet simple way to operate"

so as an alternative solution a simple formula is needed to calculate infusion droplets to prevent error rates (Wright, 2007). The use of smart pumps can reduce annual expenditure and it proved to be an alternative with lower costs compared to conventional infusion systems, this allows for savings, especially in services in the ICU (Palacios Rosas et al., 2019).

The result in table 3 also found that the majority of participants expected that the new design of the intravenous system device can be designed to stop automatically. A study stated that the infusion pump must have the ability to stop the infusion fluid that runs out automatically (Doesburg et al., 2017). Other nurses in this study expected 
that the new design of the device also to be able to monitor the remaining intravenous fluid automatically through the screen of the device. A study explained that the infusion rate was adjusted to the flow rate needed with the help of display on accuflow. The flow rate as shown by the accuflow display is checked every 15 minutes until the end of one hour, simultaneous notes from the manual reading are also made (Shroff et al., 2007).

Drops calculate automatically was also one of the features expected by nurses. A prior study reported that manually calculating infusion drops often causes errors and failure in the programming of infusion fluid therapy to patients. A case study conducted at a large hospital obtained data that the lack of confidence level of nurses in performing mathematical calculations manually related to the calculation of infusion droplets (Lee, 2008). One of the most common nurse mistakes is an error in calculating the dose of the drug and the rate of drip solution (ToneyButler \& Wilcox, 2019).

The most participant in this study expected that the design of a new device intravenous system used an alarm to monitor any trouble effectively. From the nurse's point of view, alarm sounds from a device signify something wrong about the patient's condition and it needs to be followed up clinically so that the potential for detecting problems and improving better care increase (Cosper et al., 2017). The findings on this study contradicted the results of other studies which stated that the majority of nurses agree that infusion pump alarms interfere with patient care, but perceptions about these alarms are indeed different, so it is not appropriate to apply broadly the general alarm management recommendations for infusion pump alarms to this time (Vitoux et al., 2018). A study reports that alarms on infusion pumps arise because there is no flow or excess flow, slow flow, blocked intravenous lines (Shroff et al., 2007). To make the alarm effective for a device, it should refer to World Health Organization (WHO) regulations which recommend that hospital sound levels should not exceed 30 decibels $(\mathrm{dB})$ for continuous noise and $40 \mathrm{~dB}$ (for maximum sound). At the ICU patients who need constant monitoring and by using technological advances, the measured noise level exceeds WHO $40 \mathrm{~dB}$ standards and peaks at $45 \mathrm{~dB}$, even during curfews when patients need rest (Ryan et al., 2016). An alarm at the infusion pump can be meaningful because it encourages timely responses from service providers or nurses, but the presence of an alarm can also cause problems such as noise because patients need a calm and peaceful environment to be able to rest (Graham \& Cvach, 2010). Therefore we need a tool that has a warning alarm but also does not provide significant problems with noise.

Internet monitoring was a feature expected by nurses in the results of this study. So far no infusion pump can be monitored by nurses directly at the nurse station through internet network. A study conducted an internetconnected monitoring platform for IV infusion space, this device allows doctors and nursing staff to monitor the drip parameters wirelessly. The monitored data is transmitted to commercial cloud services using the HyperText Transfer Protocol Application Programming Interface. This data is saved and visualized for ease of readability for nurses and doctors (Sardana et al., 2019). Another study learned about the intravenous infusion system with automatic control, the sensor unit is designed to interact with a centralized server so that data can be uploaded directly to the cloud so that it can be easily accessed by end-users such as medicine, patient relatives (Kumar et al., 2020)

This study also found that nurses expected the new design of the intravenous system device to be flexible for a patient who was mobilizing in wheelchairs, or when a patient was being delivered to other units for treatment. It means that the device must be practical and easy to carry. This was contrary to the design of other smart pump devices which a form was not possible to carry anywhere and the patient feels uncomfortable on the indicators of position, lighting, noise, circulation, and shape (Arimbawa \& Nugraha, 2018). One study assessed flexibility from another perspective that was a disposable infusion pump with characteristics that are lightweight, small in size, easy to use, free of external power supplies, and disposable, but there are disadvantages namely the possibility of inaccurate flow rates, lack of facilities to 
change the flow rate and volume of bolus doses to provide analgesia which provides inadequacy, the inability to track a patient's history of analgesia requests (Skryabina \& Dunn, 2006). Portable electronic infusion pumps are widely used by using a power source from the battery to power the pumping mechanism of the liquid that is connected to the infusion solution reservoir, but the accuracy of the infusion flow rate ranges from 5-8\% (Oliver, 2016).

This study also found that nurses expected the new design of the intravenous system device will be easy to use for all nurses. Tools or device that were easy to use can trigger job satisfaction of nurses. This was consistent with a study which stated that one indicator of nurse job satisfaction was working conditions, namely the presence of adequate work equipment (Patrisia et al., 2018). It was supported by another study that Smart Pump Technology ambulatory can be implemented successfully in a Home Infusion Provider in small urban and rural areas. The user states that the pump is easy to use and the potential for patient safety increases. This study also shows that Smart Pump Technology can be used effectively by patients with high levels of satisfaction (Brown et al., 2018). Sometimes the use of smart pumps iv requires a little complicated programming method, so in fact, some strategies used by nurses working in busy and emergency areas are reluctant to use them because they are considered to be time-consuming, so nurses will program them manually even with alarm devices very undesirable because it makes the room noisier and increases psychological stress (McAlearney et al., 2007). A finding shows that smart pumps that are programmed by nurses require a mathematical conversion of a low secondary infusion success rate $(55.6 \%)$, so that smart pump infusion does not have a significant effect in preventing dosage errors unless smart pumps are programmed hard that cannot be changed, they can prevent dosage errors, thereby increasing patient safety (Trbovich et al., 2010). Nurses have a responsibility for collaborative actions to provide the intravenous fluid therapy, but the problem faced by nurses in conducting proper fluid therapy management is the lack of training in therapeutic management, therefore that infusion pumps are considered as the technological resources that most contribute to patient safety (Moreira et al., 2017). This is similar to the results of the previous study, which states that nurses receive positively the efficiency of the application of smart pumps intravenous although some performance of the device is considered still less effective (Carayon et al., 2010).

In this study there was a limitation that this study was only done in one hospital, it has not fully represented the whole opinion of nurses about the new design of device expectation for the intravenous system of therapy. The recommendation of this study is that a new intravenous system device that will be designed, will be tested at this hospital as well.

However based on the results of this study can provide significant implications about the features of the new intravenous system device needed by nurses, therefore this research can continue to create a new device about intravenous systems which useful for nurses to support the implementation of nursing care effectively.

\section{Conclusion}

The new design of intravenous system device was expected have several important features and criteria based on nurse's need to support effective nursing care, this feature and criteria consist of having an economical price for patients and hospitals, have a multiautomatically system (stop automatically, monitoring remaining intravenous fluid automatically, drops calculate automatically, alarm system automatically, internet monitoring), the device must be flexible for mobility and easy to use.

\section{References}

Arimbawa, P. A. R., \& Nugraha, I. M. A. (2018). Effectiveness of the Use of Infuse Pump on Patient Comfort in Prima Medika Hospital Denpasar. Bali Health Journal, 6269. Retrieved October 28, 2019, from http:// ejournal.unbi.ac.id/index.php/BHJ/article/ 
Brown, T. D., Michael, M., \& Grady, D. S. (2018). Implementation of smart pump technology with home infusion Providers. Journal of Infusion Nursing, 41(6), 344-349. https://doi.org/10.1097/ NAN.0000000000000302

Carayon, P., Hundt, A. S., \& Wetterneck, T. B. (2010). Nurses' acceptance of Smart IV pump technology. International Journal of Medical Informatics, 79(6), 401-411. https:// doi.org/10.1016/j.ijmedinf.2010.02.001

Cassano-Piché, A., Fan, M., Sabovitch, S., Masino, C., \& Easty, A. C. (2012). Multiple intravenous infusions Phase 1b: Practice and training scan. Ontario Health Technology Assessment Series, 12(16), 1.

Cosper, P., Zellinger, M., Enebo, A., Jacques, S., Razzano, L., \& Flack, M. N. (2017). Improving clinical alarm management: guidance and strategies. Biomedical Instrumentation \& Technology, 51(2), 109115. https://doi.org/10.2345/0899-820551.2.109

Doesburg, F., Cnossen, F., Dieperink, W., Bult, W., de Smet, A. M., Touw, D. J., \& Nijsten, M. W. (2017). Improved usability of a multi-infusion setup using a centralized control interface: A task-based usability test. PLOS ONE, 12(8). https://doi.org/10.1371/ journal.pone.0183104

Giuliano, K. K. (2018). Intravenous smart pumps: Usability issues, intravenous medication administration error, and patient safety. In Critical Care Nursing Clinics of North America, 30(2), 215-224). W.B. Saunders. https://doi.org/10.1016/j. cnc.2018.02.004

Graham, K. C., \& Cvach, M. (2010). Monitor alarm fatigue: Standardizing use of physiological monitors and decreasing nuisance alarms. American Journal of Critical Care, 19(1), 28-34. https://doi.org/10.4037/ ajec2010651

Kemper, B. P. H., Koopmans, M., \& Does, R. J. M. M. (2009). Quality quandaries: The availability of infusion pumps in a hospital.
Quality Engineering, 21(4), 471-477. https:// doi.org/10.1080/08982110903152876

Kumar, D., Babu, G., Soundari, K., Priyadharsini, K., \& Karthi, S. P. (2020). A novel system design for intravenous infusion system monitoring for betterment of Health Monitoring System using MLAI. International Journal of Innovative Technology and Exploring Engineering, 9(3), 2649-2655. https://doi.org/10.35940/ijitee. c8766.019320

Lee, P. (2008). Risk-score system for mathematical calculations in intravenous therapy. Nursing Standard, 22(33), 35-42. https://doi.org/10.7748/ns2008.04.22.33.35. c6465

Manrique-Rodríguez, S., Sánchez-Galindo, A. C., López-Herce, J., Calleja-Hernández, M. A., Martínez-Martínez, F., IglesiasPeinado, I., Carrillo-Álvarez, Á., Sanjurjo Sáez, M., \& Fernández-Llamazares, C. M. (2013). Impact of implementing smart infusion pumps in a pediatric intensive care unit. American Journal of Health-System Pharmacy, 70(21), 1897-1906. https://doi. org/10.2146/ajhp120767

McAlearney,A. S., Vrontos, J., Schneider, P. J., Curran, C. R., Czerwinski, B. S., \& Pedersen, C. A. (2007). Strategic work-arounds to accommodate new technology. Journal of Patient Safety, 3(2), 75-81. https://doi. org/10.1097/01.jps.0000242987.93789.63

Morales-González, M. F., \& Galiano Gálvez, M. A. (2017). Predesigned labels to prevent medication errors in hospitalized patients: a quasi-experimental design study. Medwave, 17(08), e7038-e7038. https://doi. org/10.5867/medwave.2017.08.7038

Moreira, A. P. A., Escudeiro, C. L., Christovam, B. P., Silvino, Z. R., Carvalho, M. F. de, Silva, R. C. L. da, Moreira, A. P. A., Escudeiro, C. L., Christovam, B. P., Silvino, Z. R., Carvalho, M. F. de, \& Silva, R. C. L. da. (2017). Use of technologies in intravenous therapy: contributions to a safer practice. Revista Brasileira de Enfermagem, 70(3), 595-601. https://doi.org/10.1590/0034- 


\section{7-2016-0216}

Nuckols, T. K., Bower, A. G., Paddock, S. M., Hilborne, L. H., Wallace, P., Rothschild, J. M., Griffin, A., Fairbanks, R. J., Carlson, B., Panzer, R. J., \& Brook, R. H. (2008). Programmable infusion pumps in ICUs: An analysis of corresponding adverse drug events. Journal of General Internal Medicine, 23(S1), 41-45. https://doi.org/10.1007/ s11606-007-0414-y

Oliver, G. (2016). Optimising patient safety when using elastomeric pumps to administer outpatient parenteral antibiotic therapy. British Journal of Nursing, 25(19), S22-S27. https://doi.org/10.12968/bjon.2016.25.19. S22

Padmaja, K. V, \& Kalgal, A. M. (2013). Smart Infusion Pump: A boon to the Health Care Industry. International Journal of Engineering Trends and Technology, 4(6), 2570-2573.

Palacios Rosas, E., Soria-Cedillo, I. F., Puértolas-Balint, F., Ibarra-Pérez, R., ZamoraGómez, S. E., Lozano-Cruz, E., AmezcuaGutiérrez, M. A., \& Castro-Pastrana, L. I. (2019). Impact of implementing smart infusion pumps in an Intensive Care Unit in Mexico: A Pre-Post Cost Analysis Based on Intravenous Solutions Consumption. Hospital Pharmacy, 54(3), 203-208. https:// doi.org/10.1177/0018578718786943

Patrisia, I., Susilaningsih, F. S., \& Yudianto, K. (2018). Relationship between quality of nursing work life with nurse job Satisfaction in pilot project of nurse clinical career implementation. Jurnal Keperawatan Padjadjaran, 6(1), 25-36. https://doi. org/10.24198/jkp.v6i1.417

Pinkney, S., Fan, M., Chan, K., Koczmara, C., Colvin, C., Sasangohar, F., Masino, C., Easty, A., \& Trbovich, P. (2014). Multiple intravenous infusions phase $2 \mathrm{~b}$ : Laboratory study. Ontario Health Technology Assessment Series, 14(5), 1-163. https://www.ncbi.nlm. nih.gov/pmc/articles/.

Quitian, H., Gomez, A., Garcia Peña,
A., Arciniegas, J., Iragorri, N., Mantilla, B., Gomez-Restrepo, C., \& Rosselli, D. (2015). Cost-utility analysis of continuous Infusion Pump With Integrated Monitoring Compared With Multiple Daily Injection Treatment for Patients 15-Years or Older With Type 1 Diabetes Mellitus In Colombia. Value in Health, 18(7), A360. https://doi. org/10.1016/j.jval.2015.09.693

Ryan, K. M., Gagnon, M., Hanna, T., Mello, B., Fofana, M., Ciottone, G., \& Molloy, M. (2016). Noise pollution: Do we need a solution? An analysis of noise in a Cardiac Care Unit. Prehospital andDisaster Medicine, 31(4), 432-435. https://doi.org/10.1017/ $\underline{\mathrm{S} 1049023 \mathrm{X} 16000388}$

Safdar, A., Susilaningsih, F. S., \& Kurniawan, T. (2019). Relationship between workload performance and job satisfaction. Jurnal Keperawatan Padjadjaran, 7(3). https://doi. org/10.24198/jkp.v7i3.1178

Sardana, P., Kalra, M., \& Sardana, A. (2019). Design, fabrication, and testing of an internet connected intravenous drip monitoring device. Journal of Sensor and Actuator Networks, 8(1). https://doi.org/10.3390/ jsan 8010002

Scott Evans, R., Carlson, R., Johnson, K. V., Palmer, B. K., \& Lloyd, J. F. (2010). Enhanced notification of infusion pump programming errors. Studies in Health Technology and Informatics, 160(PART 1), 734-738. https:// doi.org/10.3233/978-1-60750-588-4-734

Shroff, P., Patel, R. D., Dave, S., Shetty, A., Dave, D., \& Jaiswal, V. (2007). Accuflow an infusion rate monitor: An evaluation in pediatric patients. The Indian Journal of Pediatrics, 74(12), 1099-1101. https://doi. org/10.1007/s12098-007-0205-9

Skryabina, E. A., \& Dunn, T. S. (2006). Disposable infusion pumps. American Journal of Health-System Pharmacy, 63(13), 1260-1268. https://doi.org/10.2146/ ajhp050408

Toney-Butler, T. J., \& Wilcox, L. (2019). Dose Calculation (Desired Over Have or Formula). 
In StatPearls. StatPearls Publishing.

Trbovich, P. L., Pinkney, S., Cafazzo, J. A., \& Easty, A. C. (2010). The impact of traditional and smart pump infusion technology on nurse medication administration performance in a simulated inpatient unit. Quality \& Safety in Health Care, 19(5), 430-434. https://doi. org/10.1136/qshc.2009.032839

Vitoux, R. R., Schuster, C., \& Glover, K. R. (2018). Perceptions of infusion pump alarms: insights gained from Critical Care nurses. Journal of Infusion Nursing: The Official Publication of the Infusion Nurses Society, 41(5), 309-318. https://doi.org/10.1097/ NAN.0000000000000295

Wright, K. (2007). Student nurses need more than maths to improve their drug calculating skills. Nurse Education Today, 27(4), 278-285. https://doi.org/10.1016/j. nedt.2006.05.007 